\title{
Traditional and modern practices in the diagnosis, treatment and prevention of animal diseases in South Kordofan State, Sudan
}

\author{
Basheir Osman Basheir ${ }^{1}$, Khitma Hassan ElMalik ${ }^{2}$, Atif Elamin Abdelgadir ${ }^{2 *}$ and Ahmed Abdel \\ Rahim Gameel ${ }^{3}$ \\ ${ }^{1}$ Ministry of Animal Resources, South Kordofan State, Sudan. \\ ${ }^{2}$ Department of Preventive Medicine and Public Health, Faculty of Veterinary Medicine, University of Khartoum, Sudan. \\ ${ }^{3}$ Department of Pathology, Faculty of Veterinary Medicine, University of Khartoum, Sudan.
}

Accepted 23 July, 2012

The present study shows at least 32 animal diseases of different etiological factors found to be prevalent in South Kordofan State. The most economically important ones are: foot and mouth disease, pox infections, lumpy skin disease, hemorrhagic septicemia, black quarter, contagious bovine pleuro pneumonia, and parasites infestations. Practically, all of these diseases have local names and most of them can be diagnosed by animal owners from the clinical signs. Traditional treatment of many animal diseases was found to be a common practice particularly herbal treatment. Tar (Gutran), Aradaib (Tamarindus mdica), Garad (Acacia nilotica) and cauterization (Kai) were the most used traditional treatment for a number of diseases and non-inflammatory conditions. The study also showed that the animal owners receive veterinary services from the government, private sector, NGOs and Community Base Animal Health Workers (CBAHWs). They are aware of all important infectious conditions and zoonotic diseases in the area as well as their treatment using veterinary drugs preparations or traditional therapies. The trial of treating natural mange infection in donkeys showed that treatment by veterinary drugs (combined drug- mangezal, cypermethrine and ivermectin paste) was most superior followed by the traditional treatment with tar (Gutran) which was considered to be the best alternative for treating mange in animals. The current study revealed that infection with blood parasites was common. $70 \%$ of bovine blood smears were positive for the blood parasites: Theileria spp., Babesia spp., Trypanosoma vivax and Trypanosoma conglense. 80, 3.7, 19.4, 16 and $7.1 \%$ of blood samples taken from sheep, goats, camels, donkeys and horses, were positive for blood parasites, respectively. In sheep and goats, Theileria spp. and Babesia spp. were detected. The prevalence was much higher in sheep. On the other hand, only Trypanosoma evansi was diagnosed in camels and only Babesia equi infection was found in equines. The prevalence of babesiosis and trypanosomosis was higher in the rainy season compared with the dry season, but that of thieleriosis in ruminants was higher in the dry season.

Key words: Animal diseases, diagnosis, treatment, prevention, Sudan.

\section{INTRODUCTION}

South Kordofan State holds huge animals wealth estimated to be 15379942 herds, mostly owned by

*Corresponding author. E-mail: atifvet@yahoo.com. Tel: 00249912110534. nomads. These provide milk, meat, skin, etc, and also act as a source of transport (equines, camels and oxen). These livestock need to be kept healthy and productive through efficient mobile veterinary services. Unfortunately, drought situations, reduction in grazing areas and tribal conflicts reduce very much the 
productivity of animals and increase their susceptibility to diseases. Foci of diseases outbreaks are becoming increasingly frequent.

Generally, livestock keepers are able to classify various diseases according to their prevalence and their adverse effects on productivity and mortality rate. Most of these diseases are given local names which are well circulated among animal breeders. The names are usually descriptive for the diseases, location of the lesions (e.g. Abu demiah and Abu lessan), their vectors (Duban disease) or the result of the infection (Abu zugalla). Animal treatment and vaccinations are basically carried out under official supervision by veterinary authorities. Thus, combating diseases depend on organized veterinary services, quick diagnosis and effective methods of treatment and control. In many localities, veterinary services are provided by the government, NGOs and private practitioners. Lack of veterinary services in areas of conflict, difficulty in providing services due to geographical factors or due to unaffordable cost of treatment, lead animal owners to resort to cheaper and available traditional treatment or to use veterinary drugs and vaccines inefficiently. This malpractice may contribute to spread of diseases and development of drugs resistance. Animal owners with limited capital resources may also seek cheaper traditional medicines (Seifert, 1987).

A simplistic definition of popular medicines or ethnoveterinary medicine is that: it is the community-based local or indigenous knowledge and methods of caring for, healing and managing livestock. This also includes social practices and the ways in which livestock are incorporated into farming systems. Ethno-veterinary medicine consists of local peoples' knowledge dealing with folk beliefs, skills, methods and practices pertaining to animal health care and production (Misral and Kumar, 2004). The active ingredients in herbs are actually similar to those in modern drugs. The difference being that, in drugs, the active ingredients are identified so that the drug contains just one or perhaps two active compounds, whereas in herbal medicines the whole plant usually used, often containing different natural compounds, giving the balancing effect which is thought to reduce the adverse side effects. Many modern medicines are originally derived from herbs and other plants. For example, for centuries, the Chinese Fir was used as treatment for asthma and bronchitis. It was not discovered until the 1800 s that it actually contains Ephedrine, a substance used in modern medicines to treat pulmonary disorders and allergies. Also, it has long been known that the bark of the White Willow had pain relieving properties. Scientists isolated the active ingredients, a group of compound called salicylates, from which they produced acetylsalicylic acid, which is now the main ingredient of aspirin. At one time, all medicines came from herbs and plants, and then science took over and found ways of artificially creating the active ingredients, giving us the medicines that we use today. In many countries of the world, there are numbers of veterinarians using herbal remedies alongside "standard" veterinary medicines. The use of the herbal remedies in the treatment of animals falls into one of two quite distinct categories of licensed veterinary herbals (Vucevac et al., 1994). The objectives of the study are:

1. To determine the most prevalent animal diseases in the area and their local names.

2. To investigate the community perception on the causes and recognition of animal diseases.

3 . To define the traditional therapeutic procedures and verify their co-existence with modern veterinary therapies.

4. To study the prevalence of blood parasites in different species of animals.

\section{MATERIALS AND METHODS}

\section{Study area}

South Kordofan State is rich in various natural resources, particularly animal wealth. The area has a great variation in climate as the northern part of the locality lies in the belt of poor savanna, the middle part in the semi rich savanna, while the southern part lies in the rich savanna belt. This variation in climate and the large animal wealth make South Kordofan State suitable for investigating animal diseases and their transmission.

\section{Soil description}

The land is formed predominantly of a flat plain soil. In the southern part of the State, the soil is muddy, with high ability to keep water for months; these places of water collection are called Ragabas. The muddy plains are intersected by patches of sandy areas called Atmour. The structure of the land changes gradually towards the north, where it becomes a mixture of mud and sand. It becomes mainly sandy in the northern part of the state and is known as Gouz or sand dunes. In the rainy season, variety of grasses grow dominantly among which are Leisag grasses (Zorina diphylla), Huskaneet (Cenchrus prieurii), Derassa (Tribulus terrestris) and Abu Asabi (Dactyloctenium aegyptium).

\section{Livestock routes}

Buggara tribes have a certain routes of movement during the journey from South to North searching for water and grasses. These routes are known as Murhals.

\section{Tribes}

The main tribes in the State are Messeria with their two main branches (Homor and Zoroug) arranged in amarat lead by Ameers (clan leaders). In the Southern part of the State, we have the Dinka and Nuer tribes. In the area of Nuba Mountain, we have the Nuba tribes e.g Kawalib, Nimung, Agang and Murou tribes. Hawazma, Kenana, Awlad Hemaid, Kawahala and Fallata tribes are also 
Table 1. Veterinary drugs used for treatment of mange.

\begin{tabular}{|c|c|c|}
\hline Drug name & Active ingredient & Dosage \\
\hline Ourofino* Injection $1 \%$ inj & Ivermectin $1 \mathrm{~g}$, q.s.to Excipient $100 \mathrm{ml}$ & By injection I.V $1 \mathrm{ml}$ for $50 \mathrm{~kg}$ body weight \\
\hline Ourofino gel ${ }^{* *}$ & Ivermectin.012 Excipient q.s.p. $9.00 \mathrm{~g}$ & $\begin{array}{l}\text { Syringe with } 9 \mathrm{~g} \text { of Ivermectin } 1.5 \mathrm{~g} \text { for } 100 \mathrm{~kg} \\
\text { body weight }\end{array}$ \\
\hline Cypervet $10 \% * * *$ & Cypermethrine $10 \%$ & $\begin{array}{l}1 \mathrm{ml} \text { to be diluted with } 1000 \mathrm{ml} \text {, repeated } \\
\text { weekly or more if necessary }\end{array}$ \\
\hline Mangezale $200 \mathrm{~g}$ & $\begin{array}{l}\text { Benzle benzoate } 10 \mathrm{~g} \text {; sulfur sublimate } 20 \mathrm{~g} \text {; } \\
\text { salicylic acid } 4 \mathrm{~g} \text {; Tar } 2 \mathrm{~g} \text {; phenol } 3 \mathrm{~g}\end{array}$ & $\begin{array}{l}\text { Repeat once daily until disappearance of } \\
\text { lesion }\end{array}$ \\
\hline
\end{tabular}

*Ourofino company Brazil; ** VAPCO company Jordan; *** AVICO company Jordan

Table 2. Traditional treatment of mange.

\begin{tabular}{lll}
\hline No. & Traditional treatment & Active ingredient \\
\hline Case 3 & Tar (gutran) & Water melon seed extract \\
Case 5 & Millet grain extract (Damerga water) & Millet extract \\
\hline
\end{tabular}

residents in the area.

\section{Animal health}

Livestock suffer, among other constrains and stresses, from a number of health problems such as infectious diseases, nutritional disorders or injuries which are handled by the owners. Help is sometimes sought from either traditional or modern veterinary practitioners to resolve these problems.

\section{Veterinary services providers}

1. Administration of animal Resources.

2. Non Governmental Organizations (NGOs) e.g. German Agro Action (GAA) (from1998 to date) and Veterinary services Organization( VSO) (2001 to date).

3. Private Sector.

4. Community Based Animal Health Workers (CBAHWs).

5. Drug Merchants.

\section{Plan of study}

This study was mainly based on the following:

\section{Structured questionnaire and personal interviews}

The questionnaire was prepared, pre-tested and applied in the study area. The data collected in the questionnaire consist of:

1. Information about the targeted peoples of the study area who are the nomads.

2. The main animal's diseases and their local names in the area of the study and the knowledge of attitude and practice about diseases symptoms as recognized by animal owners.
3. Knowledge of animal owners about drugs expiry, cheated vaccines and drugs.

4. Traditional treatment versus veterinary treatment.

5 . Nomads views about veterinary services.

\section{Records}

Secondary data on the vaccinated and treated animals were collected from the records of the Administration of Animal Resources, and NGOs Year Books.

\section{Survey of blood parasites}

Blood samples were obtained from 114 cattle, 75 sheep, 134 goats, 36 camels, 12 horses and 42 donkeys, at different times during the rainy, cold and dry seasons. Blood samples from donkeys and horses were obtained from animals brought to my private clinic. Cattle, camels, sheep and goats samples were surveyed at nomad's collection areas (markets, water sources and vaccination points). Smears were directly prepared, air dried and fixed in absolute methanol for 3 to $4 \mathrm{~min}$. The slides then were labeled and stained in $5 \%$ Giemsa's stain for $45 \mathrm{~min}$, washed, dried and examined under oil immersion objectives for detection of blood parasites.

\section{Treatment of natural mange infection}

Five stray donkeys were used. All animals showed the clinical signs of mange infection. They were divided into two groups: Group A comprised three animals which were treated with veterinary drug preparations (Table 1) using different regimes (Table 3); while group B was composed of two donkeys which were treated with traditional medicines (Tar and millet grain extract) (Tables 2 and 4). 
Table 3. Protocol for treatment of natural mange infection (Group A) using veterinary drug preparations.

\begin{tabular}{|c|c|c|c|c|}
\hline No & Case & Drugs & Dose & Duration of treatment \\
\hline 1 & Case 2 & Ivermectin $1 \%$ inj. (start on 15.1.2008) & $1 \mathrm{ml}$ for $50 \mathrm{~kg} / \mathrm{BW}$ & The dose repeated after 2 weeks \\
\hline \multirow{3}{*}{2} & \multirow{3}{*}{ Case 4} & $\begin{array}{l}\text { Cypermethrin } 1 \% \text { for wash (start on } \\
15.1 .2008 \text { ) }\end{array}$ & $\begin{array}{l}1 \mathrm{ml} \text { diluted with } \\
1000 \mathrm{ml} \text { of water }\end{array}$ & $\begin{array}{l}\text { The wash repeated after } 1 \text { week and } \\
\text { after } 2 \text { weeks }\end{array}$ \\
\hline & & $\begin{array}{l}\text { Mangezale ointment (start on } \\
15.1 .2008 \text { ) }\end{array}$ & Topical use & Repeated every 3 days for 3 weeks. \\
\hline & & $\begin{array}{l}\text { Ivermectin Gel for oral use (start on } \\
15.1 .2008 \text { ) }\end{array}$ & $1.5 \mathrm{~g}$ per $100 \mathrm{~kg}$ & The dose repeated after 2 weeks \\
\hline 3 & Case 7 & $\begin{array}{l}\text { Mangezale ointment (start on } \\
20.1 .2008 \text { ) }\end{array}$ & & Repeated daily for 3 weeks \\
\hline
\end{tabular}

Table 4. Protocol for traditional treatment of natural mange infection in donkeys (Group B).

\begin{tabular}{clll}
\hline No & Case & Drug & Repeat \\
\hline 1 & Case 3 & Gutran (start on 16.1.2008) & Repeated weekly for 3 weeks \\
2 & Case 5 & Damerga (start on 16.1.2008) & Repeated weekly for 4 weeks \\
\hline
\end{tabular}

\section{Preparation of the traditional drugs}

\section{Method of preparing Tar (Gutran)}

Traditional healers prepare Gutran by using the seeds of watermelon. Briefly, the seeds are put on a punctured based metal gallon. A vertical hole and other horizontal one are usually dug on the ground. The bases of the gallon is fixed on the vertical hole and heated for about one hour by dry dung fire. The extract is allowed to drop from the punctured base to a dish already put at the base of the horizontal hole and collected.

\section{Method of preparation millet grains extract (Damerga water)}

Damerga is prepared by first moistening the seeds of Dokhon (millet), with little water for a few hours. Then, the decorticated seeds are pounded inside a wooden mortar. The prepared decorticated seeds are placed in a dish and filled with water for three days. This water is used for washing the animals infected with mange. Biopsies were taken from the neck region by holding a flab of skin with forceps and cutting the skin on the top, then suturing (Table 5).

These were fixed in $10 \%$ formalin, trimmed and processed in paraffin. Sections 4 to $6 \mathrm{~mm}$ thick were prepared and stained with haematoxyclene and eosin (H\&E) for histopathology (Drury et al., 1980).

\section{Data analysis}

Microsoft Excel for windows 2003 was used for data analysis. Descriptive statistics (frequency and percentage) was used for all variables - cluster. Bar chart was used for some variables (source of advices and source of veterinary drugs and vaccines).

\section{RESULTS}

\section{Primary data obtained from the questionnaire and personal interviews}

\section{Local names of prevalent animal diseases in Southern Kordofan}

Animal breeder gave local names to the prevalent diseases in the area of the study. These local names seem to be well known among cattle breeders in most or all states of Kordofan. The local names are applied to viral, bacterial, mycoplasmal, fungal, parasitic and non specific conditions (Table 6). Twenty three disease analyses of various etiologies, including diseases of economic importance can be diagnosed or suspected by animal breeders in the field. Diagnosis is mainly made symptomatically. The diagnosis depends on close observation and experience of the animal breeders or attendants, older people are more skillful in this respect (Tables 7 and 8).

\section{Traditional treatment for some animal diseases in Southern Kordofan State}

Various preparations of plant origin are used; eminent among these are tamenindus medica (Ardaib), Acacia nilotica (Garad) and Hibiscus sabdariffa (Karkadai). 
Table 5. Skin biopsies taken from treated infected animals.

\begin{tabular}{lcccc}
\hline \multicolumn{5}{c}{ Date of biopsy samples } \\
\hline Case & Sample 1 & Sample 2 & Sample 3 & Sample 4 \\
\hline Case 2 & 15.1 .2008 & 21.1 .2008 & 27.1 .2008 & 7.2 .2008 \\
Case 3 & 15.1 .2008 & 21.1 .2008 & 27.1 .2006 & 7.2 .2008 \\
Case 4 & 15.1 .2008 & 21.1 .2008 & 27.1 .2008 & 7.2 .2008 \\
Case 5 & 15.1 .2008 & 21.1 .2008 & 27.1 .2008 & 7.2 .2007 \\
Case 7 & 21.1 .2008 & 30.1 .2008 & 5.2 .2008 & 16.2 .2008 \\
\hline
\end{tabular}

Table 6. Local names of prevalent animal diseases in Southern Kordofan.

\begin{tabular}{ll}
\hline Local name & Scientific name \\
\hline Al alk & Mixed infection: worm and blood parasite infection \\
Abu khanag & Hemorrhagic septicemia (H.S) \\
Abu lesan & Foot and mouth disease (FMD) \\
Al lugam or Alduban & Trypanosomiosis \\
Abu zagalla or Alwarama & Black quarter (B.Q) \\
Um kassarria or Goradia & Tick fever \\
Abu kebaida or Um doda & Faciolosis \\
Um feshefesh & Pneumonia \\
Aldiedan & Worm infestation \\
Um tebail & Peste des Pitits ruminants (PPR) \\
Gadari Al dan & Sheep pox \\
Abu geneet & Contagious bovine pleuronemonia (CBPP) \\
Um fotfot & Plant poisoning \\
Abu nini & Contagious caprine pleuronemonia (CCPP) \\
Alfahamia & Anthrax \\
Ubu egail & Arthritis \\
Um surdab & Acute pneumonia \\
Al saar & Rabies \\
Al daab & Brucellosis \\
Abu Dimaia & Rinderpest \\
Alkhadar & Heart water \\
Jarab & Mange \\
Talaf & Dermatitis \\
Al nagaf & myaisis \\
Anagma & African horse thickness \\
Goub & Ring worm \\
\hline & \\
\end{tabular}

There are many local trees and herbs which are used for various animal and human treatments. Salt, vegetable oils and cauterization are also used. Mehaia, which is the washing of special ink used to write Quranic verses on wooden surface, is used based on religious belief to treat evil eye or witchcraft (Table 9). The frequency of using different traditional treatment is shown in Table 10. Answer to the question whether nomads use traditional treatment or not, revealed $75 \%$ positive answer. At the same time, $89.6 \%$ of the nomads also use veterinary drugs, alone or together with traditional treatment.
However $81.03 \%$ of animal owners prefer to use modern treatment when readily available. It can be seen from Table 11 that there are certain plants plant fruits or seeds which are commonly used for treating various animal diseases e.g. Garad (A. nilotica), Aradaib (T. medica) and tea (Thea sinensis). Kai (cauterization) is a common practice in treating skin and muscular conditions and some other diseases. Most of these plants are given per os in liquid or solid preparations or as topical applications. Garad is the most commonly used either alone or in combination with other drugs. Methods of 
Table 7. Diseases which can be diagnosed or suspected by animal breeders in the field from the clinical signs.

\begin{tabular}{|c|c|c|}
\hline Disease local name & Scientific name & Important characteristic/ symptoms \\
\hline Um fotfot & Plant poisoning & Diarrhea, blood is black, bloat, sudden death \\
\hline Abu nini & CCPP & Cough and difficult respiration associated with characteristic by sounds. \\
\hline Abu kebieda & Fasciolosis & $\begin{array}{l}\text { Emaciation, cough, eye discharges, fall of hair, reduction in production, jaundice and } \\
\text { sudden death }\end{array}$ \\
\hline Fahamia & Anthrax & Diarrhea, bloat, blood oozing from natural orifices and sudden death. \\
\hline Ubu dagali & Heart water & $\begin{array}{l}\text { Loss of appetite, blood diarrhea, cough, increase of respiratory rate, edema of the } \\
\text { thorax, enlargement of eyes, emaciation }\end{array}$ \\
\hline Al anaba & Tumor & Tumors in joints \\
\hline Jufar & Trypansomosis & Fever, increase of respiratory rate, depression, hair fall \\
\hline Abu egail & Arthritis & Inability to walk in the morning, loss of appetite \\
\hline
\end{tabular}

Table 8. Diseases which can be diagnosed or suspected by animal breeders in the field from the clinical symptoms.

\begin{tabular}{|c|c|c|}
\hline Disease local name & Scientific name & Important characteristic/ symptoms \\
\hline Al alk & Mixed infection & $\begin{array}{l}\text { Mouth discharge, swollen eye, diarrhea, emaciation and enlargement of gall } \\
\text { bladder }\end{array}$ \\
\hline Tasammum damawi & H.S & $\begin{array}{l}\text { Swollen eyes, emaciation, bloat, nasal discharges, swollen forelimb, swelling of } \\
\text { thoracic area and death }\end{array}$ \\
\hline Abu lessan & FMD & Vascular ulcers in tongue, fever, loss of appetite, death of calves \\
\hline Um dradem & Lumpy skin disease & Nodules in the skin, fever nasal discharges \\
\hline Al lugam & Trypanosomosis & Fever, fall of tail hair \\
\hline Gradia & Tick fever & Inability to walk, hair falling, emaciation and death \\
\hline Warama/ Abu zagala & B.Q & $\begin{array}{l}\text { Mouth discharges, loss of appetite, fever, eye discharges, joint pain swollen hind } \\
\text { and forelimbs, sudden death }\end{array}$ \\
\hline Um doda & Worm infestation & Cough, enlargement of the abdomen, emaciation, rough hair, loss of milk \\
\hline Um feshefish & Acute pneumonia & Hard cough and black lung at postmortem \\
\hline Um tebail & PPR & Diarrhea, cough, nasal and mouth discharges, death \\
\hline Jadary dan & Sheep pox & Skin nodules, mouth and eye discharges, and diarrhea \\
\hline Abu geneet & CBPP & Cough with grunting, extended neck abduction of forelimb \\
\hline
\end{tabular}

preparations of these drugs include: soaking e.g. Garad and Karkadi; soaking and maceration e.g. Aradaib and Laloub; whole plant e.g garlic; salts like: $\mathrm{NaCl}$ and $\mathrm{KCl}$ provided as licks or mixed with food. Most cases are treated by the use of herbs. This indicates that herbal treatment is wildly practiced in Western Sudan. It is well known that herbs are the source of many pharmaceutical preparations and before pharmaceutical products were introduced, they have been used in many communities worldwide as the main source of medicines for the treatment of human diseases. They are cheap, available and have no or little side effects.

\section{Owner's knowledge about veterinary drugs}

Owners invented local names, some of them are descriptive, for veterinary drugs preparations e.g haba hamra is the red tablet, a name given to Ethidium preparation; safof means powder, a name given to some anthelimintics, and gamieh amrad is the drug for all diseases given to oxytetracycline. About taking 
Table 9. Traditional treatment used for some disease conditions.

\begin{tabular}{|c|c|c|c|c|}
\hline $\begin{array}{l}\text { Disease local } \\
\text { name }\end{array}$ & $\begin{array}{l}\text { Disease scientific } \\
\text { name }\end{array}$ & Medicinal preparation/ local name & Scientific name & $\begin{array}{c}\text { Outcome of the } \\
\text { treatment }\end{array}$ \\
\hline Abu lesan & FMD & Mehaia (Quran) & Not applicable & -+ \\
\hline Alguha & Pneumonia & Kai & Cauterization & + \\
\hline Al nukhama & Pneumonia & Garrd & Acacia nilotica & ++ \\
\hline Guradia & Tick fever & Ardaib & Tamarindus mdica & -+ \\
\hline Snake bites & Snake bites & Abu laila & Gardenia lutea & ++ \\
\hline Um tebail & PPR & Mehaia & Not applicable & -+ \\
\hline Huzal & Emaciation & Salt Garrad & $\mathrm{NaCl} /$ Acacia nilotica & + \\
\hline Um feshefish & Acute pneumonia & Kai & Cauterization & + \\
\hline Abu nini & CCPP & Kai Ardaib, thoum, alala tree & $\begin{array}{l}\text { Cauterization } \\
\text { Tamarindus mdica }\end{array}$ & + \\
\hline Abu dagali & - & Ardaib, tea, & Tamarindus mdica & -+ \\
\hline Um fotfot & Plant toxicity & Groundnut oil & - & + \\
\hline Isshal & Diaharrea & Garad & Acacia nilotica & ++ \\
\hline Anaba & Skin tumor & Kai & Cauterization & +++ \\
\hline Nophakh & Bloat & Ardaib & Tamarindus mdica & ++ \\
\hline Al alk & Mixed infection & $\begin{array}{l}\text { Garad } \\
\text { Tea }\end{array}$ & $\begin{array}{l}\text { Acacia nilotica } \\
\text { Thea sinensis }\end{array}$ & +++ \\
\hline Abu zagala & B.Q & Ardaib & Tamarinus mdica & -+ \\
\hline Fahamia & Anthrax & Tea, Ardaib & $\begin{array}{l}\text { Thea sinenis, } \\
\text { Tamarinus mdica }\end{array}$ & -+ \\
\hline Um sofar & Not applicable & Kai & Cauterization & ++ \\
\hline Um dradeem & Lumpy skin disease & Salt & $\mathrm{NaCl}$ & - \\
\hline Um kassaria & Tick fever & Kai & Cauterization & ++ \\
\hline Abu kotaf & Not applicable & Kai & Cauterization & + \\
\hline Um bung & Not applicable & Garad & Acacia nilotica & -+ \\
\hline Um bregango & Plant toxicity & Ardaib atroon & $\begin{array}{l}\text { Tamarinus mdica } \\
\mathrm{CaCL}\end{array}$ & +++ \\
\hline Plant toxicity & Plant toxicity & Zoofa plant & Plant toxicity & -+ \\
\hline $\begin{array}{l}\text { Tasummum } \\
\text { Aladar }\end{array}$ & Plant toxicity & Ardaib & Tamarinus mdica & +++ \\
\hline Reed & Diarrhea & Garad & Acacia nilotica & ++ \\
\hline
\end{tabular}

-+ Doubtful; + Slight effective; ++ Moderately effective; +++ Significant effective; ++++ High significant effective

veterinary advice from veterinarian, $20.69 \%$ said they always refer to a veterinarian for advice, while $22.41 \%$ said they usually do that, $48.28 \%$ said they sometimes refer to a veterinarian and $5.17 \%$ said they never ask for veterinary advice. The study showed that $41.38 \% \mathrm{knew}$ the true drugs and vaccines by the expiry date, $29.31 \%$ by asking others and $5.17 \%$ trusted their source; $1.72 \%$ knew by color while $24.14 \%$ did not know whether the drug or the vaccine is cheated or not. Concerning the viability of vaccination, only $27.59 \%$ said vaccination is available while the $68.97 \%$ denied. Regarding dead animals, the majority of the answers discard them, $(3.45 \%)$ burn them while (31.03\%) carry out necropsy.

For taking samples from sick or dead animals', only $12.07 \%$ take samples to veterinarian; samples are generally taken from the blood (5.17\%), lungs (6.90\%), liver $(5.17 \%)$, heart $(3.45 \%)$, intestines $(1.71 \%)$ or gall bladder (1.71\%) (Table 12).

\section{Veterinary services}

Animal breeders receive veterinary services from the 
Table 10. Most commonly used traditional treatment.

\begin{tabular}{llcc}
\hline Local drug name & Scientific name & Frequency & Percentage \\
\hline Mehaia & - & 1 & 1.72 \\
Ardaib & Tamarinus mdica & 7 & 12.07 \\
Garrad & Acacia nilotica & 15 & 25.86 \\
Abu laila & Gardenia lutea & 1 & 1.72 \\
Ala tree & - & 2 & 3.45 \\
Kai & Cauterization & 5 & 8.62 \\
Atroon & CaCl & 2 & 3.45 \\
Tea & Thea sinensis & 7 & 12.07 \\
Groundnut oil & - & 1 & 1.72 \\
Hemaid tree & Sclerocarya berria & 2 & 3.45 \\
Karkadi & Hibiscus sabdariffa & 2 & 3.45 \\
Quran writing & & 1 & 1.72 \\
Garlic & Allium sativum & 1 & 1.72 \\
Nabag & Ziziphus spina-christi & 1 & 1.72 \\
sald & NaCl & 1 & 1.72 \\
Laloub & Balanites eagyptiaca & 1 & 1.72 \\
Ala ala tree & - & 1 & 1.72 \\
Non & - & 2 & 3.45 \\
\hline
\end{tabular}

Table 11. Frequency of usage of traditional treatment.

\begin{tabular}{lc}
\hline Traditional preparation & Frequency \\
\hline Herbs & 40 \\
Cauterization & 5 \\
Salt & 3 \\
Religious & 2 \\
Oils (cooking oils) & 1 \\
No answer & 2 \\
\hline
\end{tabular}

Table 12. Sources of the veterinary advices.

\begin{tabular}{lcc}
\hline Source & Dry season (\%) & Rainy season (\%) \\
\hline Governmental vet. clinics & $9(15.51)$ & $21(36.21)$ \\
Pharmacies and mobile clinics & $26(44.83)$ & $19(32.76)$ \\
CBAHWs & $4(6.90)$ & $6(10.34)$ \\
Merchants & $11(18.97)$ & $9(15.51)$ \\
Anonymous & $7(12.07)$ & $1(1.72)$ \\
\hline
\end{tabular}

government, private sector, NGOs and CBAHWs as shown in Table 13.

\section{Natural mange treatment}

\section{Clinical observations}

Before treatment, the donkeys showed dirty, rough thickened and wrinkled skin located at the head and neck region. This was associated with partial alopecia.

After treatment with both traditional and veterinary drugs therapy, the skin crusts were removed and wrinkles appeared less obvious, except the one treated with Ivermectin injection. Mangezal and the combination therapy were most superior, followed by the tar application. 
Table 13. Veterinary services.

\begin{tabular}{|c|c|c|c|c|c|c|c|c|c|c|}
\hline \multirow[b]{2}{*}{ Service } & \multicolumn{2}{|c|}{ Government } & \multicolumn{2}{|c|}{ Pharmacies } & \multicolumn{2}{|c|}{ CBAHWs } & \multicolumn{2}{|c|}{ Traders } & \multicolumn{2}{|c|}{ None } \\
\hline & $\begin{array}{c}\text { Dry } \\
\text { season } \\
(\%)\end{array}$ & $\begin{array}{c}\text { Rainy } \\
\text { season } \\
(\%)\end{array}$ & $\begin{array}{c}\text { Dry } \\
\text { season } \\
(\%)\end{array}$ & $\begin{array}{c}\text { Rainy } \\
\text { season } \\
(\%)\end{array}$ & $\begin{array}{c}\text { Dry } \\
\text { season } \\
(\%)\end{array}$ & $\begin{array}{c}\text { Rain } \\
\text { season } \\
(\%)\end{array}$ & $\begin{array}{c}\text { Dry } \\
\text { season } \\
(\%)\end{array}$ & $\begin{array}{c}\text { Rainy } \\
\text { season } \\
(\%)\end{array}$ & $\begin{array}{c}\text { Dry } \\
\text { season } \\
(\%)\end{array}$ & $\begin{array}{c}\text { Rainy } \\
\text { season } \\
(\%)\end{array}$ \\
\hline Advice & $9(15.51)$ & $21(36.21)$ & $26(44.83)$ & $19(32.76)$ & $4(6.90)$ & $6(10.34)$ & $11(18.97)$ & $9(15.51)$ & $7(12.07)$ & $1(1.72)$ \\
\hline Drug for treatment & \multicolumn{2}{|c|}{$5(8.62)$} & \multicolumn{2}{|c|}{$36(62.07)$} & \multicolumn{2}{|c|}{$8(13.79)$} & \multicolumn{2}{|c|}{$13(22.41)$} & & \\
\hline Vaccination services & \multicolumn{2}{|c|}{$37(63.79)$} & \multicolumn{2}{|c|}{$6(10.34)$} & \multicolumn{2}{|c|}{$8(13.79)$} & \multicolumn{2}{|c|}{$7(12.79)$} & & \\
\hline
\end{tabular}

\section{Histopathology}

Group A: Biopsies taken from Group A animals showed thickened irregular epidermis with elongated pegs and deep dermal papillae. The hair follicles were mostly seen in the inner dermis, and hair shafts were broken; areas of epidermal necrosis were seen. Dermal edema was observed together with moderate monocular cell infiltration. Sebaceous glands were atrophied. Keratin layers were separated and lost.

After treatment with the different regimes, sections from biopsies showed intact but thickened epidermis with shorter epidermal pegs and smaller dermal papillae. Dermal edema was not marked.

Group B: Sections prepared before treatment showed thickened epidermis, with areas of necrosis and pustule formation. There was dermal edema and infiltration by monocular cells mainly lymphocytes. Hair follicles were mostly seen in the deep dermis (Figure 1). After treatment, a similar picture to that of group A was seen especially in the donkey treated with Gutran (Figure 2).

\section{Survey of blood parasites}

The prevalence of blood parasites in the different animal species examined is presented in Table 14. It can be seen that $19(16.66 \%)$ out of the 114 bovine blood samples examined were positive for blood parasites; $13(68.42 \%)$ were infected with Theileria, $4(21.05 \%)$ with Babesia and 2 $(10.52 \%)$ with trypanosomes. In sheep, 8 $(10.38 \%)$ out of 77 animals examined showed blood parasites, mainly Theileria (6 cases). 5 $(3.70 \%)$ out of 134 goats surveyed were positive for Babesia (4 animals) and Theileria (1 goat). Only Trypanosomes were detected in blood samples of camels $(19.44 \%)$ and only Babesia was seen in Equines (16.66 and 4.76\% for horses and donkeys, respectively). The prevalence of Theileriosis was highest in the hot dry season, while that of Babesiosis and Trypanosomosis was highest in the rainy season. In the cold dry season, the prevalence of all blood parasites detected was minimal.

\section{DISCUSSION}

Herbal medicine has been used from ancient times. It involves the medicinal use of plants to treat diseases and enhance general health and wellbeing. Only a very few of the healing and therapeutical or curing herbs have been studied scientifically, and because modern pharmacology looks for one active ingredient and seeks to isolate it exclusive of all the others, most of the research that is done on plants continues to focus on identifying and isolating active ingredients, rather than studying the medicinal properties of whole plants (Adams, 2005). One of the aims of this study is to determine the most prevalent animal diseases and their respective local names in South Kordofan State. It also aimed to investigate the community perception to the causative agents of these diseases and to define the traditional therapies. The last aim is to compare traditional therapies for mange infection with modern veterinary drugs. The results of the study cannot be discussed without involving the influence of the war in Darfur state, where civil strife resulted in changes in the livestock movements. Trade animals, which used to come from western Sudan to Khartoum throughout the year, changed their route to pass across the study area in South Kordofan. Hamar tribes from Northern Kordofan, who used to spend the dry season in Darfur, changed their historical route to spend the dry season in the study area. These changes in the life patterns influenced the disease prevalence and animal susceptibility to diseases. This is a fact which tallies with the expected changes of prevalence when herds are 


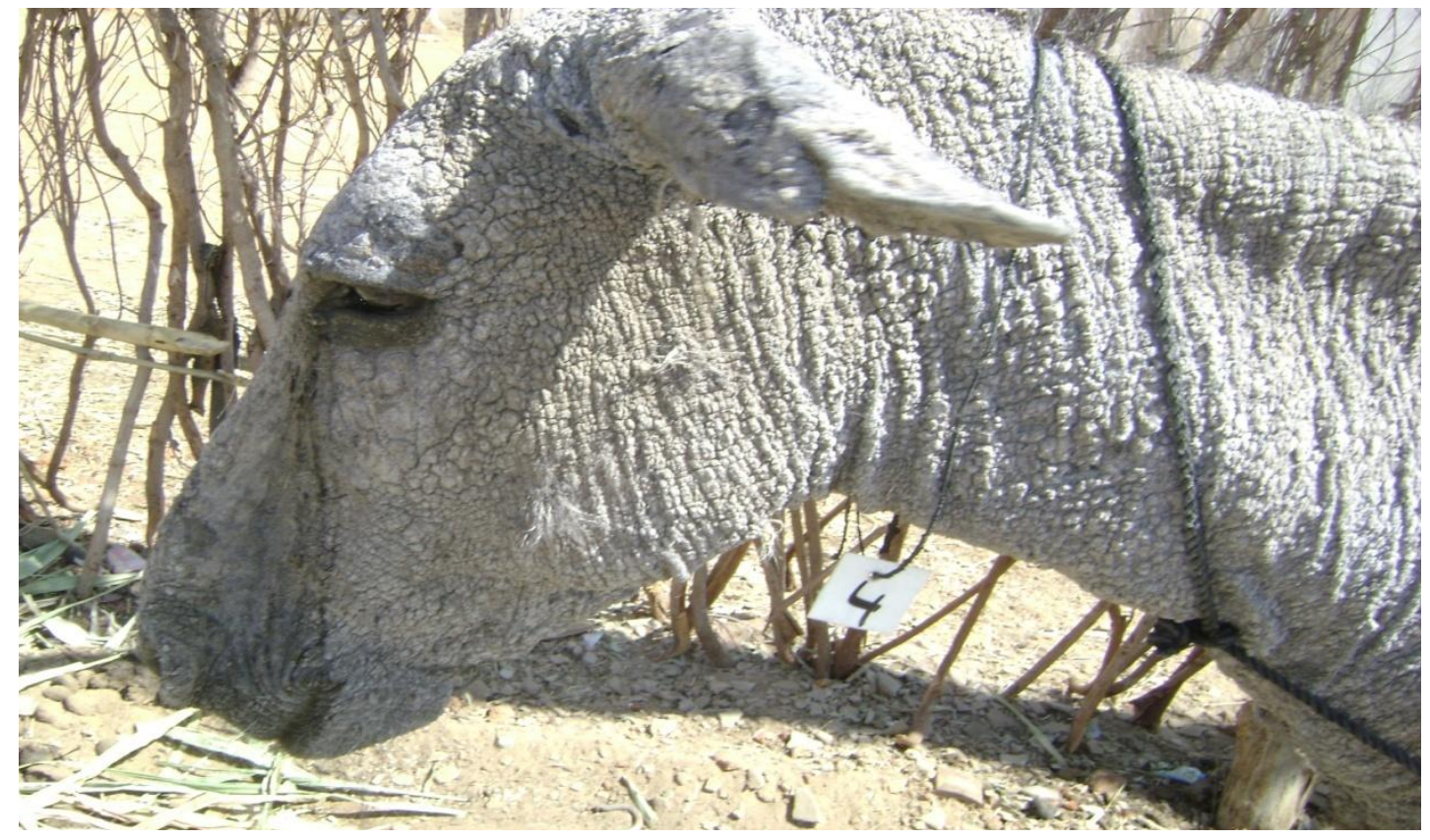

Figure 1. Case 4: Before treatment with combined drug preparation: thick wrinkled crusty skin.

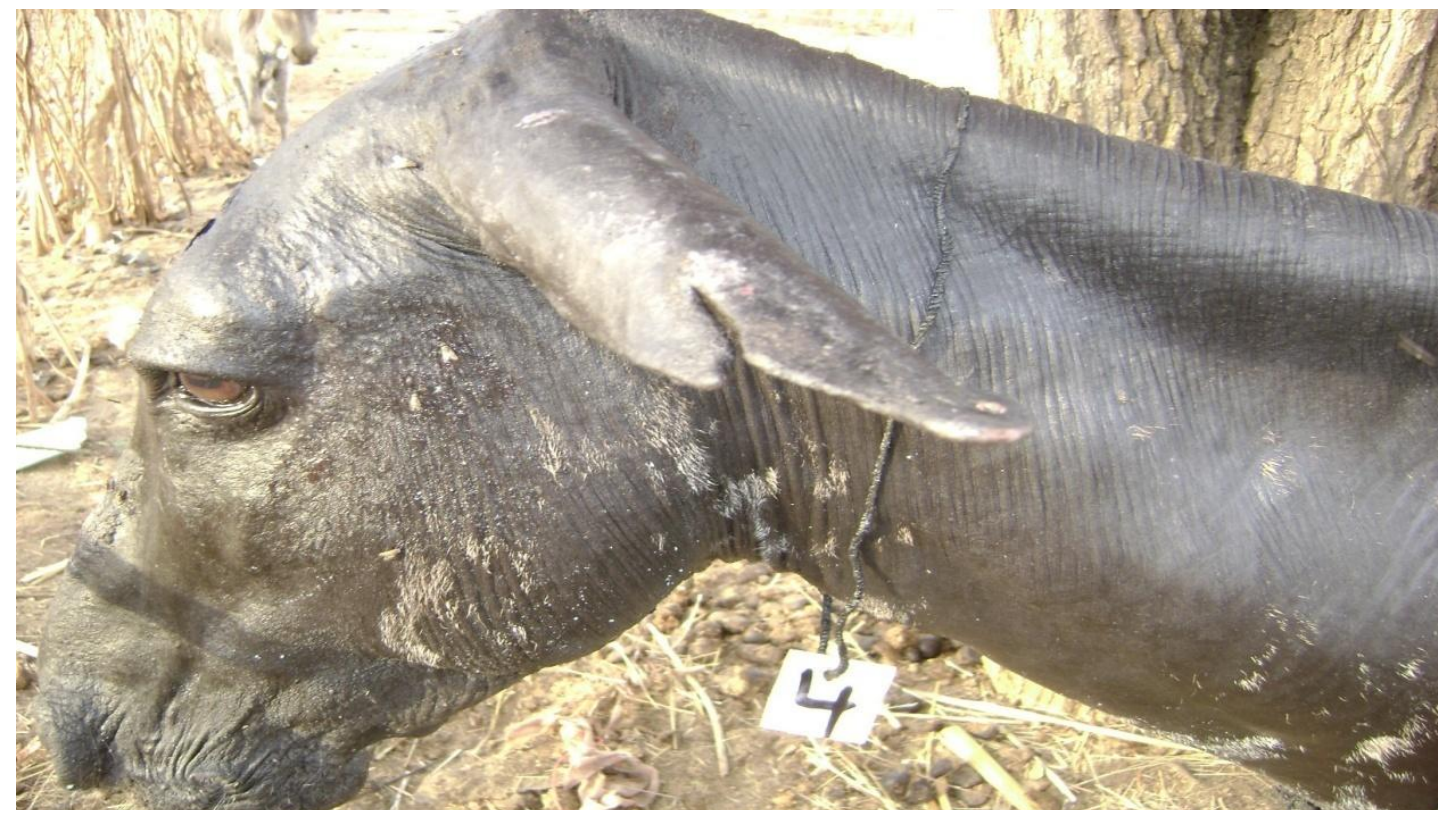

Figure 2. Case 4: Four weeks after treatment with combined drug preparation: Note loss of crusts smooth shiny skin.

introduced into a new area (Braima, 2006). In the southern part of the study area, another challenge appeared as a reflection of the civil war in Darfur Region and that is the migration of the Flatta tribes from South Darfur Region to spend the dry season in Massaif area of
Buggara tribes near Maum, Rugad and Rubkona in Unity State. As a result of this migration, many diseases appeared, such as CBPP with epidemic features.

The grazing system used by the Buggara tribes is a rotational zero grazing system which is one of the 
Table 14. Prevalence of blood parasites in different species of animal.

\begin{tabular}{lcccccc}
\hline Animal & Cases examined & Positive cases & $\begin{array}{c}\text { Percentage of } \\
\text { negative cases }\end{array}$ & Theileria & Babesia & Trypanosoma \\
\hline Cattle & 114 & 19 & 16.66 & $13(11.40 \%)$ & $4(3.50 \%)$ & $2(1.75 \%)$ \\
Sheep & 76 & 8 & 10.52 & $6(7.89 \%)$ & $2(2.63 \%)$ & $-v e$ \\
Goats & 134 & 5 & 3.73 & $1(0.74 \%)$ & $4(2.98 \%)$ & $-v e$ \\
Camels & 36 & 7 & 19.44 & $-v e$ & $-v e$ & $7(19.44 \%)$ \\
Horses & 12 & 2 & 50 & $-v e$ & $2(50 \%)$ & $-v e$ \\
Donkeys & 42 & 2 & 4.76 & $-v e$ & $2(4.76 \%)$ & $-v e$ \\
\hline
\end{tabular}

cheapest systems in animal breeding. It is also a kind of preventive practice by keeping part of the pasture clean during the wet season, where the infections, vectors and intermediate hosts are present. On the other hand, the disadvantages of this system are: the stress situation resulting from the continuous migration of animals for long distances (100 to $600 \mathrm{~km}$ ) reduces production and predisposes to disease transmission (Duval, 1994). Skerman et al. (1998) and Seifert (1996) stated that pasture rotation or pasture spelling in which livestock are withdrawn from certain areas for a period of time effectively starved the vectors and reduced their populations. These movements make the provision of veterinary services difficult, especially during the dry season where nomads go deeply into the south. In this situation, drugs and veterinary extension are almost delivered by the private sector, and CBAHWs who reach the nomads at the water sources using bicycles, donkeys, camels or on foot.

Conversely, during the rainy season, animal breeders stay around Almuglad till the middle of September. Vaccinations and extension campaigns are done by the government and NGOs. In this study, more than forty animal diseases were recognized with local names; these names were sometimes applied according to the clinical signs of the disease such as umkasarria, a name given to tick fever due to the sign of inability to walk, or due to the damage caused by the disease, like Talaf for mange disease. Some local names are applied according to the affected organ such as Abukebada for liver fluke infestation. In few cases, some local names are unexplained such as Haboub, a local name given to the lameness and musculoskeletal abnormalities (Agab, 1998). Some diseases take the name of the causative agent like Didan as an Arabic term for worm infestation. Nomads also give drugs local names. These names may be given as an expression of the efficiency of the drug like Gamiah amrrad which means the drug of all diseases. This character is also given to the oxytetracycline injection. Another name such as Safof is applied to a group of powder drugs involving tetramisole, levamisole, hexachloroethane etc due to the physical consistency of the drug. The majority of the animal owners have a good idea on the diagnosis and treatment of animal diseases; which are mainly diagnosed symptomatically. The diagnosis depends on the close observations and the experience of animal breeders or attendants; older people are more skillful in this respect. These experiences of diagnosis and treatment are carried through generations. Traditional treatment has been acquired through time by animal breeders who depend on animals for their survival and well being welfare (Cathey, 2000). Animal breeders and healers have taken advantage of the viability of many medications in the surrounding natural herbs, fruits, bark of trees, animal extracts etc. They could also recognize and describe few side effects of these medicines. Some animal diseases (viral diseases) are absolutely treated with Mehaiaand verses of Quran (Higab); this may be due to the unresponsiveness to drugs used for treating these diseases. From the result of the frequency of the traditional treatment, it can be noticed that herbs are the most common traditional medicines used by the animal owner. Many varieties and products of accessible plants, bushes and trees are available in the area which are cheap and with no or little side effects.

Comparing the coincidences of traditional therapies for traditionally diagnosed cases with proper laboratory diagnostic procedures of selected cases, is tested by treatment of natural mange infection. The result showed that the infected donkeys treated with the drug Ivermectin did not respond to treatment. This drug is commonly used by animal owners to treat ecto and endoparasites in different animal species. Some people administer the drug irrationally, giving several doses per month. Development of resistance against the drug has been suspected. However, oral ivermectin paste has been tried for treatment of chorioptic mange in donkeys. Significant reduction in the numbers of mites was observed but mites were not eliminated from all treated animals (Littlewood et al., 1995). On the other hand, donkeys treated with cypermethrin and mangzale showed the best recovery. These drugs are rather costly and not usually used by animal owners in the area of the study. Besides the treatment protocol takes sometimes.

Comparing the results of treatment with veterinary drug preparations with that of traditional treatment, it was found that treatment with Damerga was not satisfactory. 
On the other hand, application of Gutran gave the best second result after cypermethrin mangzale application, for treatment of mange. Gutran is well known all over Sudan particularly Western States. It is used for treating mange in camels by Hamer and Malia tribes, and also for curing mange in donkeys by other tribes. Thus, Gutran seems to be the most suitable and effective alternative therapy for mange in animals.

In the area of the study, blood parasites constitute a major constraint to the livestock industry. Control of these parasites is expensive, no vaccines are available, and emergence of drug resistant strains is a serious problem. The tick borne diseases: theirleriosis, babesiosis and anaplasmosis, were surveyed in this study. Because the area of the study is located in the belt of rich savanna, the suitable meteorological factors, that is, temperature, relative humidity, rainfall besides vegetation type and host grazing behavior, favor the survival of vector and transmission of disease (Tatchell and Eastorn, 1986). Braima (2006) studied the distribution of ticks transmitting theileriosis and babesiosis in the area; the most abundant tick species were Rhipicephalus sanguineus (38.60\%), Amblyomma lepidum (29.06\%) and Hyalomma marginatum rufipes $(27.91 \%)$. Other species found in decreasing order of abundance were Hyalomma anatolicum excavatum (1.25\%), Hyalomma truncatum (1\%), Hyalomma dromedarii (0.71\%), Boophilus decoloratus (0.64\%), Rhipicephalus evertsi (0.64) and Rhipicephalus simus $(0.16 \%)$. In this study, $11.40 \%$ of cattle were found infected with Theileria spp., a figure which is higher than that reported by Braima (2006) in the same area $(5.5 \%)$. In sheep and goats, the rate was 7.89 and $0.74 \%$, respectively. The prevalence of Babesia spp. was $3.50 \%$ in cattle, $2.63 \%$ for sheep, $2.98 \%$ for goats, $16.66 \%$ for horses and $6.97 \%$ for donkeys. For Trypanosoma spp., the prevalence was $1.75 \%$ for cattle and $19.44 \%$ for camels. It is noticed that the prevalence of Theileria was higher $(68.42 \%)$ in the dry hot season when compared with that in the wet rainy season $(23.07 \%)$. This is supported by the findings in the same area; Abdella (2002) found a high population density of ticks in the hot dry season of the year. He also found that the vectors Boophilus and Rhipicephelus showed their maximums rates of prevalence from May to August and from December to February, respectively. One important factor is that nomads do not have a planned strategy for control of ticks. Similar to cattle, the prevalence of Theileria infection was higher in sheep during the dry hot season (50\%). Goats appear to be refractory to infection as only one case was diagnosed. The prevalence of Babesiosis is associated with the activity of various tick vectors. Osman et al. (1982) reported highest prevalence of Rhipicephlus in the wet rainy season in Kordofan region. Similarly, the prevalence of Ambylomma lepidum, Amylyomma varigatum and Hyalomma teunctum was found to be high during the wet rainy season (Hoogstraal,
1956). Abdella (2002) and Braima (2006) reported a high infection rate during the wet rainy season in South Kordofan State. Our findings seem to agree with those of Braima (2006) who reported infection rate of $75 \%$ for goats and $66.7 \%$ for horses and donkeys. Halphin (1975) reported high prevalence of Babesia infection in cattle in the late dry season and he related that to starvation as a predisposing factor. Trypanosoma evansi was found in cattle $(1.7 \%)$ and camels $(19.44 \%)$ in the wet rainy season coinciding with the high intensity of tsetse fly in this period of the year.

As mentioned earlier, South Kordofan State is heavily populated with animals and constitutes a junction for many animal routes and intersecting area for many tribes. Many animal diseases prevail in the area and need collaborative efforts between government authorities, animal owners and NGOs for their control. The latter is achieved mainly through vaccination and treatment of sick animals. In some situations, veterinary services are usually inadequate and this makes animal owners more prepared to receive veterinary care from NGOs. This study has shown that NGOs have provided considerable valuable services by vaccinating large numbers of animals, especially cattle, against many viral and bacterial diseases and by treatment of sick animals. The efforts of NGOs are complementary but sometime they surpass that provided by official governmental services. They contributed a lot to the animal health and welfare. In areas of conflicts, the security status is poor and this hinders provision of veterinary services to animal owners and also makes traditional medicines popular. These medicines are cheap, constantly available and easy to prepare and use. Although many animals' owners believe in folk medicines, their faith in modern chemotherapy seems to be stronger. Folk medicines are more practiced by the poor. Failure of treatment may help spread diseases resulting in focal outbreaks. However, in situations where veterinary services cannot be provided, traditional medicines may become the only available alternative. These medicines should be well studied and their efficiency promoted. Scattered information about traditional treatment (source and applications) can be gathered and their therapeutic value assessed scientifically. Livestock keepers can take an acute part in this process as they have a good deal of knowledge about animal diseases, their diagnosis and treatment by available methods (Weiser, 1994).

\section{Conclusions}

1. Many animal diseases are prevailing in South Kordofan including protozoal, viral and bacterial diseases.

2. Animal owners are well aware of animal diseases and have good experience and skills in diagnosis and 
treatment of these diseases.

3. Most of the diseases (viral, bacterial and parasitic) have local names (mostly descriptive names).

4. Nomads are well aware of modern chemotherapy and its applications.

5. Treatment with folk medicines becomes popular in situations where veterinary services are inadequate, that is, in areas of conflicts and due to geographical factors.

6 . Most of the traditional medicines are herbs, bark of trees or seeds of other plants.

7. Some of the folk medicines can be suitable alternatives for modern treatment (that is, Gutran for treatment of mange).

8. Although many animals owners believe in folk medicines, they prefer modern chemotherapies when they available.

\section{RECOMMENDATIONS}

1. More detailed studies for folk medicines to know their active ingredients and properties.

2. Experiments to see their therapeutic value and side effects.

3. Manufacture of these drugs in suitable preparations.

4. Vast animal disease surveillance in the study area to complete the listing of the diseases prevailing in South Kordofan State.

\section{REFERENCES}

Abdella E (2002). Epidemiology and ecology of ticks and some tickborne diseases in (Kadogli and Delling Province) South Kordofan State. Master of Veterinary Science Thesis, Faculty of Veterinary Medicine, University of Khartoum: pp. 39-51.

Adams K (2005). Revival of traditional treatment through herbs. www.naturalnews.com/009805.html

Agab H (1998). Traditional treatment methods of camels in Eastern Sudan with emphasis on firing. J. Camel Pract. Res. 5:161-164.

Braima I (2006). Prevalence of parasitic diseases in cattle in Abyei area - Sudan. Master of Veterinary Science Thesis, Faculty of Veterinary Medicine, University of Khartoum 29:110-113.
Cathey A (2000). Learning about Liei: participatory diagnosis of the chronic wasting problem in cattle in southern Sudan. Participatory diagnosis: a fertile method for investigating cattle wasting diseases in Southern Sudan. www.participatoryepidemiology.info/.../Liei-ReportSouthern-Sudan.pdf

Duval J. (1994). The control of internal parasites in ruminants www.AGRO - BIO -370 - 04E. 22:1-2, 22:6-11.

Halphin B (1975). Pattern of animal diseases 2nd edition. Bailliere. Tindal, London.

Hoogstraal H (1956). African Ixodide, Ticks of Sudan with special references to Equatorial province and with preliminary review of the genus Boophelus, Margropus, and Hyalomma. U.S. Washington D.C. pp. 582-599.

Littlewood DJ, Rose J, Paterson S (1995). Oral Ivermectin paste for the treatment of Sarcoptic Mange in horses. Vet. Record. 137(26):661 663.

Misral KK, Kumar AK (2004). Ethno-veterinary Practices among the Konda Reddi of East Godavari District of Andhra Pradesh. J. Tribes Tribals 2(1):37-44.

Osman OM, El Husssein AM, Ahmed N, Abdulla HS (1982). Ecological

Seifert HS (1987). The combating of animal enzootics diseases in the tropics -A balance and perspective. Anim. Res. Dev. 25:35-44.

Seifert HS (1996). Theileriosis.In: Tropical animal health 2nd edition Kluwer Academic publisher, Netherland pp. 180-200.

Skerman PJDG, Cameronand F, Riiveros H (1998). Tropical Forage Legumes 2nd edition FAO plant production and protection series 2, FAO Rome pp. 442-443.

studies on ticks (Acarina, Ixodidae) of Kordofan region. Sudan. Bull Anim. Health Prod. Afr. 30:45-53.

Tatchell RJ, Eastorn E (1986). Tick (Acari: Ixodidae) Ecological studies in Tanzania. Bull. Entomol. Res. 76:229-246.

Vucevac B, Karlovic V, Citation M (1994).Traditional methods for the treatment of animal diseases in Croatia. Rev. Sci. Technol. 13(2):499-512.

Weiser A (1994). Animal diseases control in Eastern Sudan. Anim. Res. Dev. 39:135-143. 